\title{
Discussion of Difficulties or Problems in Calculation and Analysis of Water Efficiency of Irrigation
}

\author{
Wenxue $\mathrm{He}^{\mathrm{a}}$, Chaqing $\mathrm{Li}^{\mathrm{b}}$ \\ Zhejiang University of Water Resources and Elctric Power, \\ Hangzhou, 310018,China \\ ahewx@zjweu.edu.cn, blichq@zjweu.edu.cn
}

\begin{abstract}
The water efficiency of irrigation is a main index that measures the farm water use efficiency, because of many factors affecting the calculation and analysis, a lot of difficulties or problems have been met. This paper is based on the work of the calculation and analysis of irrigation water use coefficient in Hangzhou, the difficulties or problems met in actual work have been analyzed, the constructive recommendations or measures have been given. changing concepts and strengthening technology force should be the key that the reliability result of calculation and analysis will be advanced.
\end{abstract}

Keywords-farm irrigation; water efficiency of irrigation; calculation and analysis

\section{PREFACE}

The water efficiency of irrigation is a ratio of a net applied water that has been used by crops in once or some time and total irrigation water quantity that come from a water source or canal head, it is related to natural conditions, project status, level of water management, irrigation technology and other factors [1], it is a efficiency index of agricultural water use, and is also an important index of irrigation management capabilities and technical service levels. "Technical guidance rules in calculation and analysis of national irrigation water efficient utilization coefficient (2013.12)"(it will be hereinafter referred to as the "technical guidance rules ") will be a programmatic document guiding the national irrigation water efficient utilization coefficient calculation and analysis work, is based on the early test results of the national irrigation water efficient utilization coefficient calculation and analysis, has a some maneuverability. However, there are the differences in the terrain, topography, level of socio-economic development, crop growing conditions and irrigation habits, some practical difficulties and problems had been still encountered in the irrigation water efficient utilization coefficient calculation and analysis work.

\section{DIFFICULTY OR PROBLEM}

\section{A. Poor Awareness of Water Saving, Idea Lag Of Water Saving \\ The traditional habits of flood irrigation still exists, many local people including some government officials}

don't realize "using more water, more wastewater produced”, poor awareness of water saving and idea lag of water saving has become an important factor to properly resolve the current water problems, the idea should been first solved in the irrigation water efficient utilization coefficient calculation and analysis work.

Water resource is relatively abundant in the southern region, the geographical advantage to have no lack of water in the history and the management model to don't charge for irrigation water have engendered the poor habits that don't attach importance to agricultural water efficiency and water saving, but also makes the water pollution problems to be particularly prominent with the rapid economic and social development. In fact, the agricultural production model to use a large number of fertilizer and pesticides meet with the irrigation methods of "flood irrigation, irrigation at the same time in drainage", the non-point source pollution is brought by agricultural irrigation also increasingly, manurial and agricultural production had been affected on certain level. In this regard, deserves great attention of leaders.

\section{B. Having Difficulties in Precise Calculation Methods}

The recommended approach in "Technical Guidance Rules" is "determination and analysis in head and tail", this method only needs to analyze the net irrigation quantity and the gross irrigation quantity, the water efficiency of canal system and water efficiency in field have been avoided, the actual test work has been simplified, but encountered problems or difficulties in practical work is as follows.

\section{1) Statistical Period of Time and Time Presenting} Reports

The statistical period of time has been stipulated by "Technical Guidance Rules", the calendar year has been used, that is January 1st to December 31st every year, the results report of calculation and analysis must be presented at the end of a year. Rainfall data and related statistical data, the rule of water requirement in the crop growth will all affect the analysis results of the irrigation water efficient utilization coefficient. But through continuous observation and test in a long year, the reliable value of irrigation water efficient utilization coefficient in a certain area will be achieved. 


\section{2) Selecting Sample of Irrigation Area and a Typical Field}

Sample of irrigation area and a typical field is the basis for analyzing the irrigation water efficient utilization coefficient, and its importance goes without saying, but more difficulties at an operational level had been met in the implementation process. The choice principle to be provided by "Technical Guidance Rules" to sample of irrigation area is "representativeness, feasibility and stability", but also the number, type, scale about sample of irrigation area have been explicitly stipulated too. Because of the influence of topography, household production and other aspects, it is difficult to fully meet the requirements of these principles in the actual operation.

According to "Technical Guidance Rules", the sample of irrigation area should be equipped with the measuring water facilities, but the construction of the measuring water facilities has lagged, misunderstanding of ideas, deficiency in technology, restricting in reality make the selection of samples irrigated areas facing difficulties. The number, location, size and shape etc. at a typical field have all clearly been defined in "Technical Guidance Rules", but it will be restricted by the topography, farmer's planting habits and other factors in the implementation process. For example, if the sown area of some crops exceeds more than 10 percent of the total sown area, the typical field planting these crops must be separately selected, it is difficult to meet this requirements.

The reason is that planting crops is comparatively scattered, farmers had been given more freedom in planting crops, the restricting measure in planting management is lack. Moreover, the data on planting area and actual irrigation area will be obtained by a stepwise statistical manner, the accuracy of the data may be a certain deviation, and the final calculation of the net irrigation water will be affected.

3) Net irrigation Quantity and Gross Irrigation Quantity

The net irrigation quantity means that irrigated into the field and can be directly absorbed by crops, it can be determined by using "method of direct measurement " or " method of observation and analysis". The irrigation quota that has been obtained by irrigation experiment station will be a good references, the data accuracy has a certain assurance. But the "Technical Guidance Rules" has emphasized that the net irrigation quantity averaged each mu in a typical field should be usually obtained by using the method of a direct measurement, the field test is more difficult in the condition of the actual agricultural environment and personnel level.

The gross irrigation quantity is the total amount of water that draws from the headwaters. the "Technical Guidance Rules" has emphasized that the gross irrigation quantity should be determined by the method of a water measure. But for some irrigation area, the irrigation headwaters is not unique, the channel obviously skip a grade, the gross irrigation quantity that derive from some minor headwaters can only be obtained through statistics. In addition, the water system is flourishing in a south, the irrigation often directly get water from the water system, the water needs of farmers can be met by barrages or a small irrigation pumps anywhere (except for the mountains or special dry season), the calculation of gross irrigation quantity will have a direct impact, which is a factor to control most difficult on the actual work.

4) Copious Irrigation and Deficient Irrigation

In the calculation of water efficiency of irrigation, estimating copious irrigation and deficient irrigation is the prerequisite to accurately obtain the net irrigation quantity averaged each mu in a typical field. The method recommended by "Technical Guidance Rules" is to contrast the net irrigation quota ( $M$ ) with the net irrigation quantity averaged each mu ( $w$ ). If $k \cdot w \geq M$, then the copious irrigation is considered, take the net irrigation water $w_{j}=M$; If $k \cdot w<M$, then the deficient irrigation is considered, take the net irrigation water $w_{j}=k \cdot w$. Here, $k$ is the reduction coefficient, for drought crops $k=0.9$; for rice, $k=0.9 \sim 0.95$. This approach is built on the basis of the empirical results in view of certain test, for a typical field, the net irrigation water $w_{j}$ which has built on the basis of the field trials will rely on the measuring flow facility and dedicated and responsible testing personnel, these are indispensable, but, some difficulties have been still existed in practical level.

In addition, for the rice field using water-saving irrigation technology, the farmland soil may be in a non-saturated state during irrigation, more water will infiltrate the soil[2], measuring ${ }^{w_{j}}$ will be more difficult, and the determination on the depth of wetting layer is also difficult[4], the change of soil moisture content should be measured in a field, there is not only a heavy workload in the test, but also it is not easy for a farmer to master the test technology, which is another practical difficulties affecting the calculation results.

\section{Difficult to Accurately Reflect the Influence of Hydrological Condition}

The farmland irrigation is easily affected by rainfall, and a rainfall has the characteristics of the uneven distribution in time and space. The relationship between yearly rainfall amount and rainfall amount of a major crop growth period in sample of irrigation area may not be stationary, this will directly affect the irrigation water coefficient of a larger area that has been obtained in samples of irrigation area. The research findings[3] on Zhang River Irrigation District in Hubei have been indicated that the level of irrigation water use coefficient will be significantly affected by the hydrological regime.

\section{More Difficult to Control the Return Water}

Irrigated farming is comparatively convenient for farmers in south, rice cultivation has been accustom to irrigation and drainage at the same time, the drainage may flow to natural river or water networks again, the problem of the return water in the irrigation maybe arises, the 
amount of utilization and deduction will be difficult to determine in practical work.

For this reason, the water efficiency of irrigation to take a small watershed as a computing unit has been denominated in the literature [4]. But for the plain river network, there almost is not a clear watershed boundary or the watershed boundaries are extremely far away, water efficiency of irrigation so a large range will become more complex, diverse factors will make analysis and calculation change more difficult.

\section{E. Observers at the grassroots Have a Relatively Low Level}

Because the work calculating water efficiency of irrigation presently started, the relevant organizations, institutions and funds have not been fixed yet, so that the majority observers who have been arranged in sample of irrigation area by the relevant counties (cities, districts) are older man, their education level is lower, the investigators also not fixed, the summary of the relevant statistics or observational data is often difficult.

There are reasons in two aspects; one is that literate young adults in rural have been migrant workers now, on the other hand the wages or remuneration paid by the water conservancy department is lower. There is a larger difference between the level of actual technicians and the requirement in calculation and analysis, which will directly affect the working quality and the level of measurement.

\section{METHODS AND SUGGESTIONS}

(1) Strengthening management to the sample of irrigation area and a typical field

Selecting the sample of irrigation area and a typical field is the basis to analyze water effective utilization coefficient.

In addition to requirements of "technical guidance rules", the sample of irrigation area and a typical field that have been submitted by the counties (cities, districts) should been examined by the relevant experts, and will be brought into the provincial checklist of the sample of irrigation area, appropriate irrigation management system should be executed, the unified management should be implemented, so that they can be remained a relatively stable. Meanwhile, the planting crops in the sample of irrigation area should be examined, and the irrigation water quantity in the sample of irrigation area and a typical field may be controlled by a certain engineering measures, the government department should lend support to the measurement and analysis about water efficiency of irrigation from the aspect of personnel, technology and funds. The relative test conditions should be closer to the irrigation experiment field, the tillage measure and the level of irrigation facilities should be commensurate with the irrigation area of the same type and technical level in this region, so that they can maintain stability, reflect typicalness and have representativeness. The checklist of the sample of irrigation area will carry out dynamic management, implement the annual audit, and ensure that the location and quantity of the sample of irrigation area satisfy the requirements of "technical guidance rule".

(2) Making arrangements for specialized personnel, strengthening technical training and guidance

The test and statistics about Net irrigation quantity and gross irrigation quantity are the core to calculate and analyze the water efficiency of irrigation, but the observation and experiment of the water quantity in the samples of irrigation area and a typical field are also a relatively disperse work, which maybe continue a longer time and is always liable to be affected by a weather, and according to the requirement of planting crops and farmers the observing work should carry out at any time.

For this reason, the observation and record in the sample of irrigation area must arrange a special worker, the cultural level and work attitude of the observers should be raised a claim, on the premise of job training and professional qualifications the observer will be able to work, the accurate and reliable crop acreage, the actual irrigated area, irrigation water quantity and other measuring records will can be reported, and the data processing and materials collecting can be submitted in accordance with the relevant provisions, so that the calculating results in the samples of irrigation area and the typical field can achieve the appropriate level.

(3) Strengthening scientific propaganda, pushing the work of the calculation and analysis

The calculation and analysis of irrigation water use coefficient is an important part of the national water saving strategy, leaders at all levels must give a great importance, and through a forceful science popularization, the importance of water saving in agriculture should be comprehended by farmers, it is understood in particular that the water saving in agriculture is an important measure to reduce non-point source pollution and improve fertilizer use efficiency.

The traditional technology of flooding irrigation may not be able to increase yield, the bad habits on irrigation at the same time in drainage must reduce fertilizer efficiency, meanwhile, this will turn the natural clean water into outlet water to contain a great deal of nitrogen, phosphorus and other nutrients, and the water area will be easily threatened, this is one of the major force behind the water eutrophication, strengthening the popular science on the water saving is very urgent and necessary.

(4) Strengthening technical support force, exploring the work program with local conditions

The analytical work of water efficiency of irrigation involves in the experimental observation and analysis calculation, the grass roots department or technical support unit generally report that there is technical difficulties in practical work.

Such situation had been encountered in actual work, the cross-sectional shape and size of irrigation channels, bottom slope, roughness, flow conditions on upstream and downstream ,the flow pattern had all been not considered, measuring weir had been selected by only the channel width, so that the result of flow measurement by measuring weir don't meet the technical requirement. The actual 
situation of irrigation channels must be taken seriously researched in the actual work, and the flow measuring facilities can be selected according to hydraulics analysis, only in this way the accuracy of flow measurement will be able to ensure.

Therefore, the technical support forces of grassroots must be strengthened, the method about calculation and analysis that has been stipulated by "technical guidance rule" must be known well, and the work can be creatively achieved according to the actual situation of local irrigation area. Meanwhile, the program of work that has a good applicability can be gained, with the help of the reliably measure results, the healthy development of the local economy and society will be sustainable.

\section{REFERENCES}

[1] National Working party of calculation and analysis about water efficiency of irrigation. The technical guidance rule about the national calculation and analysis about water efficiency of irrigation.Beijing,China,2013.12.

[2] FAN Junjiang; ZHOU Gang;WANG Jie. Improvement on measuring methods for irrigation water utilization efficiency in irrigation areas. Advances in Science and Technology of Water Resources, Vol.33(2013)No.6,p.44 47.

[3] CUI Yuan-lai,TAN Fang,WANG Jian-zhang. Comparision of irrigation efficiency under different scales. Journal of Irrigation and Drainage, Vol.29(2010)No.1, p.5 10.

[4] Xie Qinghua. Study on irrigation water use coefficient in the small mountainous watershed. China Rural Water and Hydropower, (2011)No.3, p.33-34. 